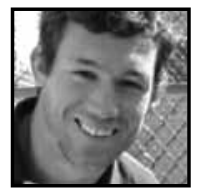

\title{
Teaching With Portals: the Intersection of Video Games and Physics Education
}

\author{
Cameron Pittman, LEAD Academy
}

\section{ABSTRACT}

The author, a high school physics teacher, describes the process of teaching with the commercial video game Portal 2. He gives his story from inception, through setbacks, to eventually teaching a semester of laboratories using the Portal 2 Puzzle Maker, a tool which allows for the easy conception and construction of levels. He describes how his students used the Puzzle Maker as a laboratory tool to build and analyze virtual experiments that followed real-world laws of physics. Finally, he concludes with a discussion on the current and future status of video games in education.

\section{Introduction}

n June of 2012 I interviewed for my current teaching position at LEAD Academy, a charter high school in Nashville, Tennessee. During my interview, I made it clear that I wanted to teach physics using video games as part of the curriculum. Well before I had even heard of LEAD or sent in a resume and cover letter, I had planned a semester of laboratories set inside the virtual world of Valve Software's commercial video game, Portal 2. During the interview I told the principal that I fully intended to use a video game in a way that no other teacher had ever considered; I wanted to use Portal 2 as a laboratory setting.

It seems self-evident. Video game realism, simulation ability, and availability have vastly improved in recent years. Video games showcase how realistically they resemble the world, both graphically and interactively. It seemed like a natural jump to take physics education to a readily available and flexible medium. To this day, I am 
still surprised that the idea had not taken root elsewhere. There are a few educators who have, in similar fashion, turned video games into physics laboratories. But none were high school teachers, and none had taken it to the same scale I wanted.

Fortunately, the principal supported my crazy idea and hired me.

\section{Background Information}

Students come to us with the built-in capability to become fully immersed inside game worlds. They spend upwards of hundreds of hours poring over every mission and detail of games. Why not use the same skills and game worlds to teach them? If we can reroute their attention from killing each other (an all-too-common video game theme) to productive, educational activities, then video games become a huge asset to educators. The leap is small and surmountable, especially with Portal 2, which is essentially a series of physics puzzles, one after another (Portal 2 [Computer software], 2011).

In the Portal series, consisting of the original Portal and Portal 2, the player takes on the role of a test subject from the first-person perspective who has to navigate through a series of increasingly challenging experiments known as "test chambers." These experiments generally consist of modular rooms with an entrance and an exit. Upon entering a room, the player must find, open, and reach an exit. Sometimes the challenges are simple, such as placing a cube on a button to open a door.

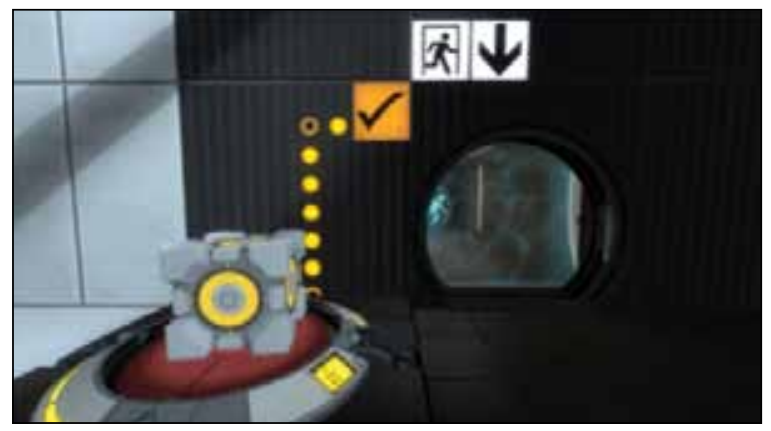

Fig. 1: Cube and button mechanics opening a door

Other times the challenges are more difficult and may require the use of one or more elements, such as automated (and apparently sentient) gun turrets, springloaded launchers (called aerial faith plates), lasers and laser receptors (called thermal discouragement beams), tractor beams (called excursion funnels), and gels that change the elasticity of surfaces or the rate at which objects accelerate on surfaces. 


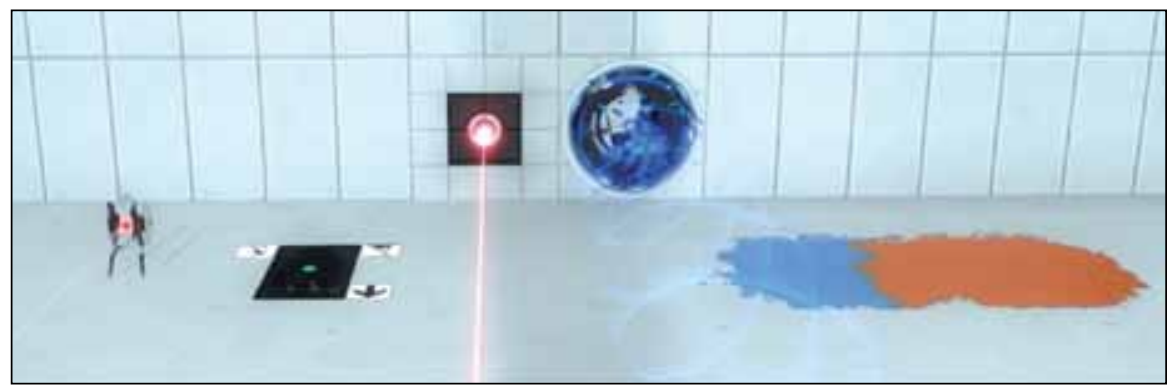

Fig. 2: From left to right: a turret, an aerial faith plate, a laser, a tractor beam, bounce gel, and speed gel

The only tool available to the player is the portal gun, formally known as the Aperture Science Handheld Portal Device (so named by Aperture Science, the fictional corporation holding the player hostage and hosting the experiments). The portal gun allows players to connect two surfaces with a wormhole, which they can use to traverse distant points instantaneously. Furthermore, any speed an object has upon entering one portal is conserved as it exits the other. Combined with the various game elements, the player has to rethink geometry and physics to move about rooms in ways that are impossible in real life.

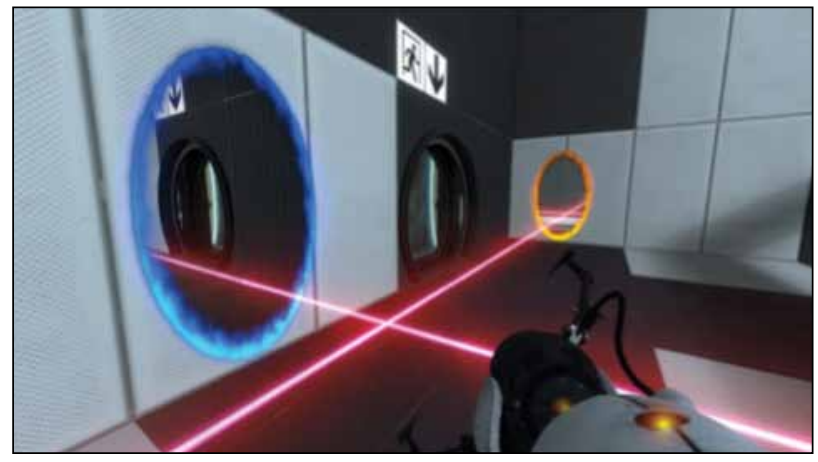

Fig. 3: A laser going into the orange portal and exiting the blue portal. Also, notice the portal gun in the foreground.

One basic gameplay technique is called the momentum fling, which requires portals on two surfaces, one being horizontal (such as a floor) and the other vertical (such as a wall). A typical momentum fling will require the player to place one portal well below her current position, usually in some type of pit or below a ledge, and the other high on a wall or similar surface. The player then falls down towards the low portal, accelerating under the influence of gravity. As she enters the low portal 
and exits the high portal, she maintains her high speed and is flung across whatever room or challenge that must be crossed (see Figure 4).

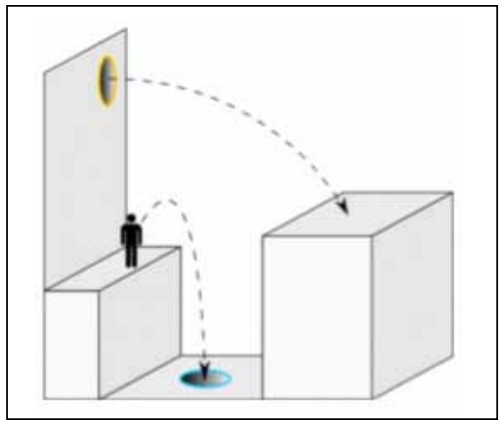

Fig. 4: A diagram of a momentum fling (Portal, n.d.)

Game developers have recognized that the easiest way to make ultrarealistic games is to engineer game worlds that follow the laws of physics (Bourg, 2002, p. ix). Physics engines handle background physical laws, serving as a sort of underlying matrix governing properties of objects and their interactions inside the game world.

There are numerous examples of physics engines in use by modern games, one of which is Valve's Source engine. Portal 2 runs on Source (Portal 2 [Computer software], 2011). While Source does not significantly stand apart from other modern physics engines in terms of technological capabilities, Valve has added features that inadvertently make it the perfect solution for classroom physics simulation.

Building content with the tools game developers use is a tedious and timeconsuming process for good reason. Games are meticulously designed to include all the nuances developers need to create an immersive and believable experience (Bourg, 2002). It takes a significant amount of time for a novice to learn how to create a basic room with four walls, a ceiling, and a floor using a program called Hammer, Valve's world-creation tool for Source. A new level designer faces a steep learning curve and tedious work to create simple levels due to the amount of freedom afforded to the user. However in May 2012, Valve released the Portal 2 Puzzle Maker, which simplifies the level design process into a point-and-click venture (compare Figures 5 and 6). What the Puzzle Maker lacks in terms of level of detail compared to Hammer, it more than makes up for in terms of ease and intuitiveness (Vic, 2012). 


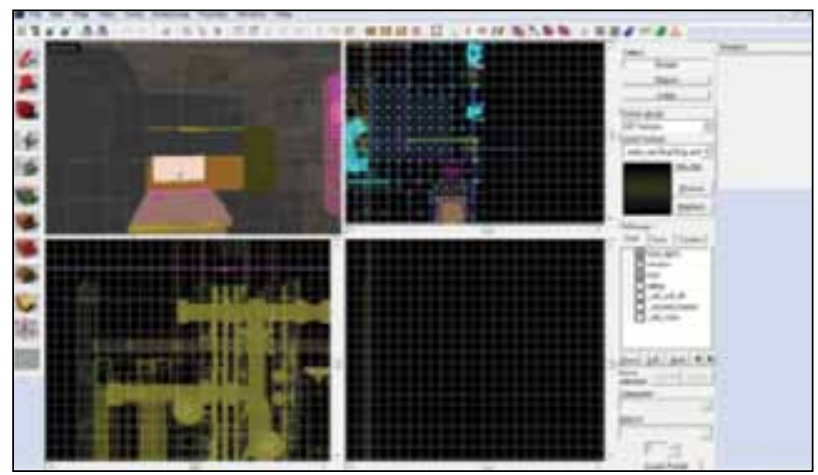

Fig. 5: A typical Hammer workstation

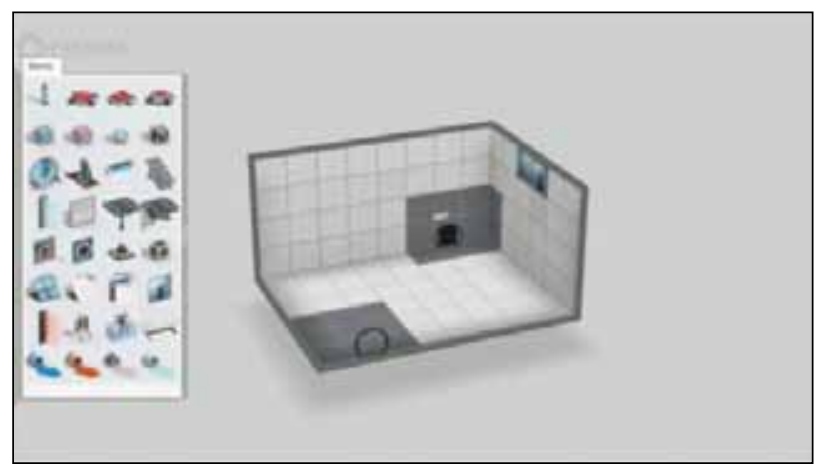

Fig. 6: How all Puzzle Maker levels start

The Portal series is incredibly successful in terms of critical reception and sales, with more than 8 million units sold in total (Caoili, 2012) and garnering scores of 90 and 95 out of 100 for the original and sequel respectively on Metacritic (CBS Interactive, $2013 \mathrm{a} / \mathrm{b}$ ). Soon after the original game's release, Valve realized that its customers wanted more puzzles than they could reasonably deliver (Valve Software, 2012). The single player campaign lasts on average around nine hours (GameLengths, 2013). Valve released the Puzzle Maker under the title "Perpetual Testing Initiative," indicating the ease with which the gamer community could contribute an essentially limitless reservoir of challenges (Wilde, 2012).

\section{Teaching History}

As I was finishing my second year of teaching in 2011, I reevaluated my methods. Had my students participated in enough labs? Did their problem-solving skills improve throughout the year? I realized that I wanted a better laboratory situation. 
My school, like many other high-needs high schools, suffered from a severe lack of funding. The laboratory equipment I inherited was in disrepair, while other muchneeded tools were missing altogether. Ordering equipment was a painfully slow and frustrating endeavor. I wanted a fast, dynamic, and easy way for my students to interact with concepts from their lessons and solve problems. Without readily available physical laboratory supplies, I turned to digital learning.

I tried illustrating difficult concepts with basic flash game simulations such as those found at Colorado University's PhET. ' While they entertained students as diversions from usual lessons, student results were still disappointing, whether due to the flash games' inherent lack of utility in the classroom or my inexperience as a teacher, I could not determine. And I was unhappy using simple flash games. Physics, and science as a whole, are connected experiences. No idea exists in isolation; all of the laws of physics we currently understand branch from the same four fundamental forces (which may well be consolidated further, but that is a discussion for a completely different journal) (Weisstein, 2007). Presenting ideas in science in single-serving packages ignores the underlying connections that make science the beautiful, cohesive fabric of the universe we want our students to appreciate. So, I thought bigger.

I realized that I wanted to teach with a physics simulator, a world in which my students could interact with as many laws of physics as possible. It quickly dawned on me that a modern video game, with all of its physics engine flexibility, would provide the perfect platform. I thought of the original Portal. By the end of the summer, I had written a full set of laboratory lesson plans using Portal's test chambers.

I initiated contact with Valve in the summer of 2011. In my first email, I gave them a copy of my Portal lesson plans and asked for feedback, requested a class set of copies of Portal, and asked how my students might be able to export position and time data of different objects in the game world to make for easy calculations. Valve soon replied with a demonstrated interest in education and supported me as I tried to teach with Portal and later Portal 2.

At the start of the 2011-2012 school year, I began preparing for Portal 2 physics lessons. I suspected that Portal 2 could run on the school's laptops, but I could never test my hypothesis because they were under strict control. Software installation required administrator access, and there was never more than one IT administrator in our building at any given time. And when he was there, his attention was split between the hundreds of computers, printers, projectors, and luddites in the building. 
Administrator access was a secondary concern to the real issue: the school's locked-down network. In order to install Portal 2 in the first place, a computer must have access to Valve's content distribution program, Steam. Steam communicates with Valve's servers to download and activate software through a range of network ports, which were unfortunately blocked.

Over the course of the school year, I fought to open the ports. My previous principal fought on my behalf too, but we collided with a bureaucratic mess in the district office. Promises were made to open the ports but the district failed to follow through.

I was just as disappointed as my students that we were never able to make Portal 2 a laboratory setting in the 2011-2012 school year. But, I did not want to waste all of my efforts. To compensate for unavailable classroom resources, I instead brought my personal desktop computer to school to allow students to run through lessons on a trial basis. I pulled students aside one at a time during independent work and allowed them to work their way through some sample levels. As they got more familiar with the game, I encouraged students to start building simple experiments in the Puzzle Maker.

I noticed the Puzzle Maker's power early in the sample lessons. One student, with problematic communication skills but exceptional problem-solving capabilities, wanted to build a level. After a few minutes of playing with Portal 2 he concocted a level design. He tried but ultimately failed to verbally explain it to me. However, after five minutes of work with the Puzzle Maker, he managed to build a complicated system of linked buttons and cubes to make a set of six excursion funnels which cyclically switch directions at regular intervals.

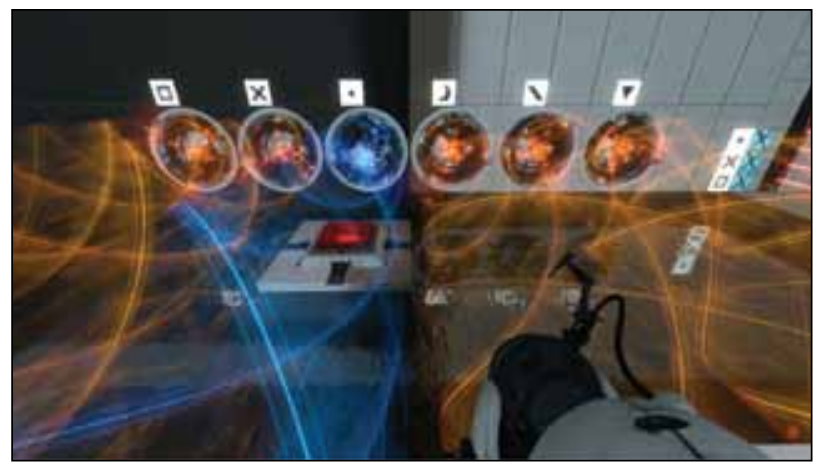

Fig. 7: My student's cyclical excursion funnel level. The colors of the excursion funnels represent their direction. About every second, the blue funnel turns to orange and the orange funnel to the right turns blue. 
While this student's verbal communication lacked clarity, he obviously had a clear understanding of the game's internal logic. This was a tangible example of how the freeform aspects of the Puzzle Maker empower students to express themselves and work in a way that no other tool can replicate with the same ease and broad applicability.

\section{Current School Year and Selected Laboratory Overview}

Following the release of the Puzzle Maker, I started creating a set of physics lessons in which students explicitly conceptualize, build, and analyze experiments within the Puzzle Maker. ${ }^{2}$ Topics covered included velocity, acceleration, friction, gravity, forces, momentum, energy, and projectile motion. The power of the Puzzle Maker lies in the ease with which it allows users to create content, making students masters of their own design who can quickly create and manipulate worlds to try new ideas and draw conclusions.

The 2012-2013 school year began in sharp contrast to my previous three years as a teacher. For testing purposes, my new school has a classroom set of recent model MacBook Pros. And because of our charter, we have full control over our resources, including network ports. Two weeks in the 2012-2013 school year, I had successfully installed Portal 2 on a class set of laptops and was prepared to start Portal 2 laboratories.

Portal 2 lessons began with a preview of sorts in which students were encouraged to independently explore the game's campaign and sample levels to gain comfort and confidence. From there, we used the Puzzle Maker in the natural progression of laboratories that would typically be found in a first semester high school physics class.

In their first official Portal 2 lesson, students studied the time it takes a falling object to reach the ground. Students were instructed to build a level that would allow them to easily observe the entirety of a falling object's path. They had to predict how long it would take the object to hit the ground using the same laws of physics that dictate motion in the physical world. The primary goal of the lab was to help the students develop an implicit trust in the game's physics engine. I wanted them to see, in a very easy way, that the game world accurately simulates the real world. As a secondary goal, I also observed the ease with which students interacted with the game. Unsurprisingly, they demonstrated a range of abilities. Some students were exceptionally adept with Portal 2 with likely extensive video game experience, while others struggled navigating through the menus. 
Portal 2 succeeds as a physics laboratory simulator because students can collect accurate data inside the game world. Portal 2's utilitarian and futuristic laboratory motif naturally leads itself to mathematically precise architecture. Square panels permeate the game's floors and walls, creating perfect metrics for measuring distance (see Figure 8).

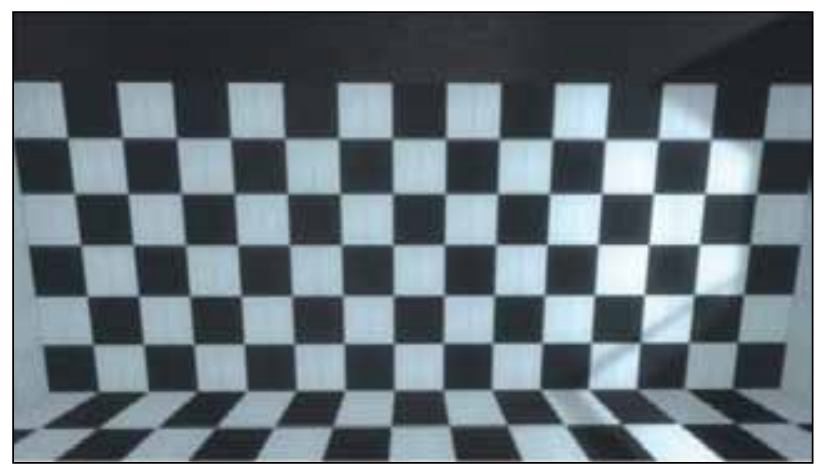

Fig. 8: A checkered wall and floor to illustrate the all-pervasive square-shaped panels in the Puzzle Maker.

Motion is, in effect, the study of how and why displacement changes over time. Counting panels gives us displacement. To complete the time component of motion, the educational version of Portal 2 features a built-in stopwatch.

In the second laboratory, students worked backwards from the first lab to calculate the strength of gravity. They built ledges at known heights from which they could drop and time objects falling to the ground. Students knew what answer to expect ahead of time because they had been given the strength of gravity in the game world in the previous session.

Even with the work I had done to create the labs, I still had to justify using a video game to teach all of the Tennessee state standards for physics, including the math and laboratory skills standards (Metropolitan Nashville Public Schools, 2013). Students performed data collection and analysis on every experiment, including this one. Students had to time multiple object drops from each height and take the average for their calculations. Quantitative error analysis was beyond my students' skill sets at this point, but we still discussed the reasoning for taking multiple measurements. Students performed the laboratory with objects falling from different heights to ensure the strength of gravity is independent of altitude or other quirkiness in the game world. 
From their work with basic concepts in motion, we moved on to forces. The Portal games offer the unique ability to create infinite loops, whereby an object falls into one portal with the exit portal directly above (see Figure 9). In this scenario, the object falls indefinitely through the portals while accelerating under the influence of gravity. Eventually, it appears to reach some type of terminal velocity.

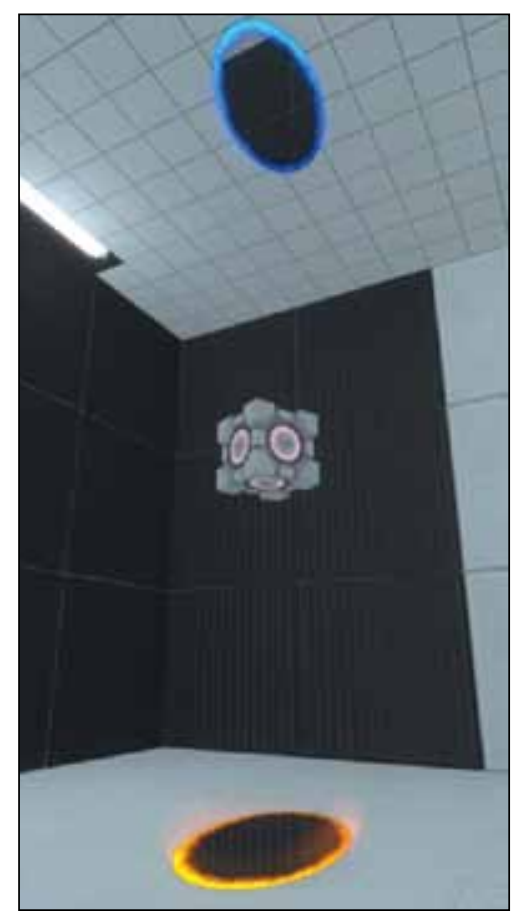

Fig. 9: A cube falling through an infinite loop. Note the position of the two portals.

In the terminal velocity laboratory, I challenged my students to determine terminal velocity by simply measuring the distance between two horizontal portals placed directly on top of one another and recording the amount of time it takes to make five falls through their portals. Students allowed themselves to fall for a moment to ensure they had reached terminal velocity before starting the timer.

My students learned their first physics quirk of Portal 2: portals have a speed limit. In most infinite falls, the player never reaches a terminal velocity because the game itself imposes a maximum speed with which a player can exit a portal. Though subtle, many of my students noticed that portals slowed them like speed bumps as they fell. 
The data supported their claims. Students realized that falls from different heights (e.g., where portals are at varying distances apart) led to different terminal velocity measurements, which runs counter to expectations in the real world. They found that greater vertical distances between the two portals produced higher measured terminal velocities. This lesson stuck with students. On their next quiz, I asked them about the cause of terminal velocity in the real world and received a few responses about the speed limit portals impose. I am always happy to see students remembering classroom experiences but it goes to show the power careless teaching can have. Playing with video games is especially like playing with fire; students remember what happens in them, so teachers have to carefully filter information.

From lessons on terminal velocity and forces, we moved on to collisions and momentum. In this laboratory, students launched objects of different masses and velocities at each other with aerial faith plates (see Figure 10). We ran into some technical difficulties. In the early days of Portal 2 lessons, my students used the normal version of Portal 2 distributed with Steam for Schools, only called the Portal 2 Educational Build at the time because it limited online features. Later that semester, Valve released new features for the Educational Build that introduced, among other items, contraption cubes with variable mass, friction, and elasticity. Contraption cubes would have been a tremendous asset for the collision experiment because cubes were the easiest objects to successfully and cleanly collide (and not to mention, variable elasticity opens up additional experiments). Without contraption cubes of customizable masses, my students used turrets and spheres (otherwise known as "edgeless safety cubes") because of their varied masses: cubes have a mass of $40 \mathrm{~kg}$, turrets have a mass of $85 \mathrm{~kg}$, and spheres have a mass of $100 \mathrm{~kg}$. My students found that spheres and turrets tend to rotate or shift either before launch or in midair causing glancing rather than head-on collisions.

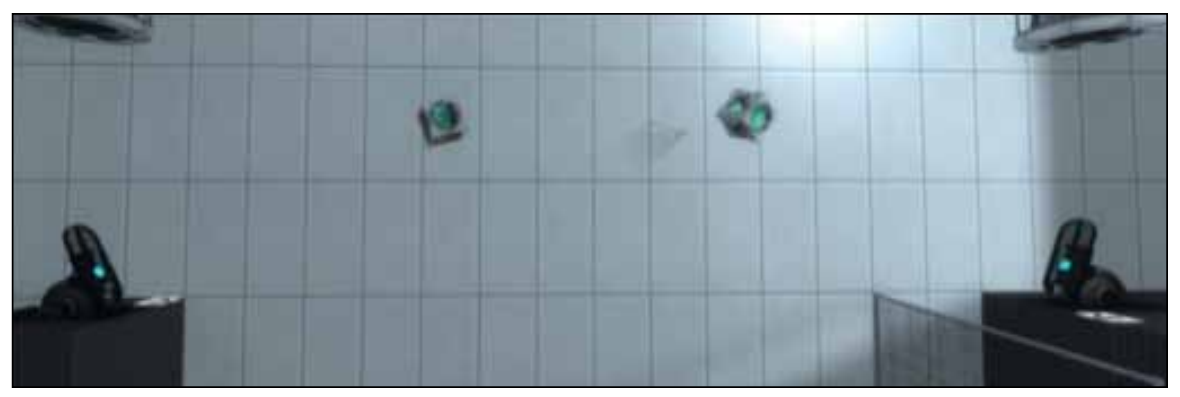

Fig. 10: A typical test of the law of conservation of momentum. The cubes are flying directly at one another. 
Though the Source engine handles momentum and collisions extremely well, glancing blows with turrets and spheres frustrated students. Some drew incorrect conclusions because they failed to see successful head-on collisions, which I had to later correct in class.

The new version of the Educational Build includes the on-the-fly ability to alter the rate at which time passes for in-game objects (not including the player). But prior to the release of the new version, my students still needed to slow down time to capture the velocity of moving objects at the instant of launch or immediately after. I taught them how to use the developer console, which is a command line interface for altering the game world. Students enacted console commands to slow down time and pull information about moving objects directly from the physics engine. They took to the console surprisingly well, but the educational build's new time variables hastened data collection.

In the next laboratory, students built off their knowledge of independent velocity vectors to predict where launched objects would land. Portal 2 handles projectile motion accurately. While their experiments succeeded and students related launch angle, launch velocity, and distanced traveled, I saw a surprising number of students simply copy the demonstration level I made. There are numerous ways to launch objects in Portal 2 , such as by using momentum flings, aerial faith plates, repulsion gel (which causes objects to bounce), propulsion gel (which causes the player to accelerate more than normal) and ramps, or simply running and jumping off a ledge. I used an aerial faith plate in my example and most of my students followed suit. Had students spent more time exploring the game on their own before entering the world of laboratory lessons, I believe my copycat issue would have been mostly mitigated. Part of the draw of using the Puzzle Maker is the ease with which students can realize their own creations; I wanted to see my students create unique contraptions, not rehashed designs (more on this in the Issues, Setbacks, and Lessons section).

The last major addition to the Educational Build worth noting is the more accurate aerial faith plate design. In the vanilla build of the Puzzle Maker, players predetermine the landing spot for the aerial faith plate simply by placing a target. Regardless of mass, objects land in the same place. 


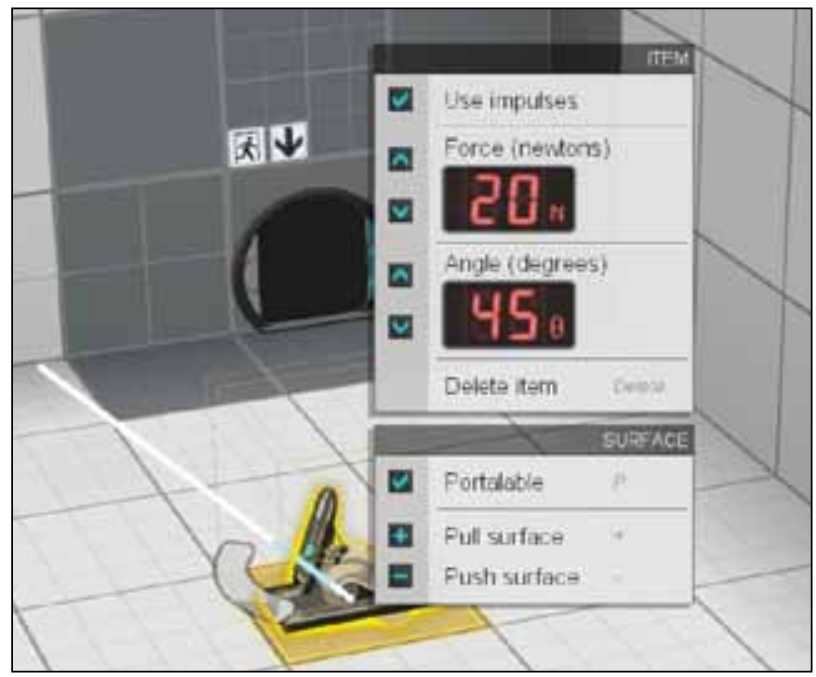

Fig. 11: Aerial faith plate "impulse" options in the Puzzle Maker

The Educational Build adds "impulses" which ostensibly allow you to alter the angle, measured in degrees, and force, measured in Newtons, of aerial faith plates. With locked forces, objects of different masses accelerate differently upon launch and land in different places. When I first saw "impulses," the forces listed caught my eye. The force of the aerial faith plate can be slid between 1 and 99 Newtons.

I knew immediately that aerial faith plates represented "impulses" incorrectly. I continue to use quotation marks because the "impulse" listed is actually a force. An impulse is a force over time and has units of Newton-seconds. So, I designed a laboratory exercise where students investigate the inaccurate nature of aerial faith plates. Students observed that aerial faith plates appear to launch objects for a split second but calculated that aerial faith plates would have to accelerate objects for more than 400 seconds to achieve the same effect. They quickly identified that something was amiss.

When students examined their data, they asked with apprehension if their calculations were accurate. "Yes," I told them, "but what does that say about the way aerial faith plates work in the game?" Students compared their results to what they expected, one of Tennessee's embedded inquiry standards, and quickly found the game world failed to realistically represent all aspects of the real world. Though physical inaccuracies may seem like a downfall, when students identify what aspects of the game are unrealistic, they apply their understanding of physics at a much deeper level. 
For the essay portion of their semester exams, my students built levels in the Puzzle Maker that showcased multiple concepts learned throughout the semester. Students chose two or three concepts we covered and built levels demonstrating said concepts. They also wrote essays to describe the concepts in question and explain how their levels demonstrated them. Physics is incomplete without quantitative analysis; so all students also wrote their own physics problem and built an accurate representation of it in their level, which they then solved.

Some students produced polished, clean levels (see Figure 12). Other students produced impressive messes with extraneous features and unclear physics. In both cases, I graded students on their ability to describe the physics of their levels and some of the best scores came from poorly designed levels.

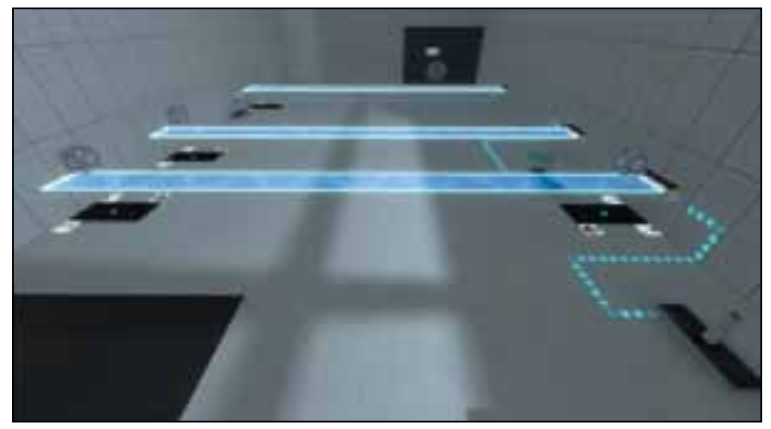

Fig. 12: An overview of a clean winter final level. Note the three tests in succession.

I analyzed my final exam for the accuracy with which students answered questions on topics we covered with the Puzzle Maker. Selected, non-normed results from the multiple-choice section are as follows in Table 1:

Table 1:

Topics Covered With Puzzle Maker

CONCEPT

One Dimensional Motion

$56 \%$

\begin{tabular}{ll}
\hline Forces & $40 \%$ \\
\hline Momentum, Conservation of Momentum & $91 \%$ \\
\hline Conservation of Energy (including work) & $50 \%$ \\
\hline Projectile Motion & $53 \%$
\end{tabular}


My students performed admirably, but with ample room for improvement. My final was difficult and, as any physicist will tell you, multiple choice and physics mix like oil and water. In the essay section of the final, students earned an average of $63 \%$ of the points available. A significant portion of points were lost simply because students omitted essay sections; many of the essays that had been finished to completion featured impressive explanations of the physics demonstrations they created.

The data from the winter final is inconclusive. I feel comfortable stating that the Puzzle Maker improved my students' understanding of physics, but to what degree and with what success compared to the traditional lab is still to be determined.

\section{Classroom Effects}

Feedback from students indicated they enjoyed class. They said they looked forward to class and many of them told me they enjoyed physics more than they thought they would. Interest in physics spiked throughout the building as my students shared what was happening in class with their friends. Students from lower grade levels (and even some elementary aged siblings) asked me about next year's physics classes wondering if they could play video games in class.

While my students worked with Portal 2, classroom management issues were virtually nonexistent. Almost all students focused all of their time and energy on their work. Even the loudest and most obnoxious students actively participated for the entirety of each lesson. Students listened carefully to instructions, helped me troubleshoot a few technical difficulties, and produced high quality work. On numerous occasions, students took on tutorial roles unprompted. They worked until the end of class and, in fact, often complained that I ended lessons too early (usually to engage in post-laboratory discussions), which was a welcome change from usual classroom complaints.

\section{Issues, Setbacks, and Lessons}

Using technology without touchscreens, I watched my students flounder and flail trying to control their computers. They lacked basic skills, like keyboarding and mouse handling. Students demonstrated an aversion to using a physical mouse and almost universally preferred using the laptop touchpad to control the player's in-game view.

I found that student inexperience with video games in general, or firstperson games specifically, created the biggest setbacks to learning with Portal 2. 
A few students struggled to even grasp a sense of their position and view within the game world, which made simple tasks, like navigating a room, almost insurmountable obstacles.

Inexperience with specific gameplay mechanics and elements, such as the various tools and objects encountered in tests of Portal 2, led to unimaginative experiments. Like all classroom teachers, I have a finite amount of time to teach a large set of standards. Students enjoyed less than a single 90-minute period of free play before we began laboratory exercises, which was not enough. Granted, many of the first laboratories were written so that they would gain experience with the game, but they needed more time to feel comfortable with the often complex nature of Portal 2.

In each laboratory, I learned my expectations for student proficiency with the Puzzle Maker were too high and that my instructions were too short. I thought my students would immediately gravitate to the Puzzle Maker and demonstrate advanced world-building skills by the end of the semester. I was wrong. Students still advanced in both physics problem-solving ability and level design proficiency, but not to my expectations. If I teach with Portal 2 or any other video game again, I will go out of my way to ensure students get more time to become familiar with the game before beginning graded lessons.

\section{Conclusion}

We waste valuable resources when we fail to harness our digital natives' seemingly innate ability to interact with technology and lose themselves in game worlds. Through careful planning, science teachers can create a classroom environment where students manipulate digital worlds to create measurable scientific experiments that run on laws of physics. It is a unique opportunity for educators. We can let students play, create and interact with worlds only limited by their imaginations. They can explore and analyze impossible yet physically accurate situations to uncover real physical laws. They can build virtual experiments as valid as their physical counterparts in less time and with less effort. Teaching physics with Portal 2 is about encouraging students to actively build, explore, and apply laws of physics.

As a physicist and teacher, I think we have only just started to explore the range and depth of lessons that can be taught with video games. I see this past semester as a proof of concept-evidence that students can learn physics in a 
rigorous and realistic video game environment. I cannot overstate how much fun it is to give students a sandbox world that follows the laws of physics. The freedom of the Puzzle Maker for physics students is akin to the freedom of a pen and a pad of paper for English students. They have agency and ability to mold a world to their specifications, analyze it, share it, and ultimately learn from it in a way that no other tool can replicate.

In each of the ten laboratories, students explored the laws of physics using new tools that are only now available. The Portal 2 Puzzle Maker represents a major step towards a symbiotic relationship between the video game world and education. Video games support education by providing a practical, flexible, and readily available medium for learning. Portal 2 is just one example of a commercial video game finding applicability in a classroom. Other teachers have used games like Minecraft (Knapp, 2011), World of Warcraft (Whitcomb, 2008), the Civilization series (Alexander, 2010) and SimCity (Siddiqui, 2013) to teach topics as wide ranging as economics, history, and social sciences.

Entering the classroom gives video game developers the chance to hone their ability to create experiences that connect with all people, not just gamers. New audiences provide new challenges, which surely push developers to innovate. Education and video games both strive to create memorable experiences and leave lasting impressions on people's lives. The two disciplines have much to learn from each other.

I finished the semester feeling both invigorated and slightly daunted by the complex task facing future educators. We clearly have an impressive new technology that affords educators unique opportunities for reaching students, but we have yet to fully understand or utilize its capabilities. Video games are another medium for conveying information. They are neither inherently good nor evil, useful nor useless. The form and message of the information embedded in video games determines utility, which informs teachers how and when to apply them as effective classroom tools.

Successful classrooms of the future will mix teachers and video games seamlessly, where students will be led through virtual worlds by real teachers. These teachers will help students draw from their virtual experiences to better understand the real world. Educators and video game developers need to collaborate to innovatively intertwine video games and education. The process has already begun, with educators like Histrionix's Rick Brennan (Brennan, n.d.) and Arizona State University's 
Sasha Barab (2009) working with developers to design games made specifically for the classroom that emphasize the teacher's input. They recognize that no educational software will succeed in a classroom if the teacher has not made it their own.

I successfully taught with Portal 2 because I leveraged my intimate knowledge of the Portal universe and real-world physics to ensure that virtual experiences and physical applications complemented one another. In that sense, video games are not standalone educational tools; they are field trips, laboratories, and everyday experiences rolled into one, creating opportunities for students to draw connections and gain deeper understandings.

Accordingly, establishing the effectiveness of and improving educational video games should rely on metrics that measure game-classroom interactions rather than specific learning outcomes, which are too closely tied to individual teachers. Measuring a game's ability to retain attention, induce engagement, and apply to real-world lessons will prove invaluable as we better design and understand video games as educational experiences. Ultimately, large-scale quantitative analysis and comparative studies of learning outcomes between traditional and video game centric classrooms will ascertain the true utility of video games in education.

The nascent study and use of video games in education has indicated that video games have a profound ability to engage students and create memorable, teachable experiences. I suspect that as research continues, more educators will recognize video games as a valuable tool and my students' experiences with Portal 2 will soon be commonplace in classrooms around the world.

\section{Notes}

1. Please see: http://phet.colorado.edu/

2. Available for download at www.teachwithportals.com 


\section{References}

Alexander, B. (2010, October 6). Teaching with a video game: the case for Civilization. Retrieved from http://blogs.nitle. org/2010/10/06/teaching-with-a-videogame-the-case-for-civilization/

Barab, SA., Gresalfi, M., \& Arici, A. (2009). Why educators should care about games. Educational Leadership, 67(1), 76-80.

Bourg, D.M. (2002). Physics for game developers. Sebastopol, CA: O'Reilly.

Brennan, R. (n.d.). Histrionix. Retrieved from http://www.histrionix.com.

Caoili, E. (2012, May 8). Portal 2 has sold over 4M copies. Retrieved from http://www. gamasutra.com/view/news/169967/Por tal_2_has_sold_over_4M_copies.php

CBS Interactive. (2013a). Portal for PC Reviews. Retrieved from http://www.metacritic. com/game/pc/portal

CBS Interactive. (2013b). Portal 2 for PC Reviews. Retrieved from http://www.metacritic. com/game/pc/portal-2

GameLengths. (2013). Time to finish Portal 2 (single player campaign). Retrieved from http://www.gamelengths.com/games/ playtimes/Portal+2+(single+player+cam paign)/

Knapp, A. (2011, April 5). Using Minecraft as a Teaching Tool. Retrieved from http://www. forbes.com/sites/alexknapp/2011/04/05/ using-minecraft-as-a-teaching-tool/

Metropolitan Nashville Public Schools. (2013). Science Academic Standards. Retrieved from http://www.mnps.org/Page57420.aspx

Portal. (n.d.). Retrieved from Wikipedia: http:// en.wikipedia.org/wiki/Portal_(video -game)
Portal 2 [Computer software]. (2011). Bellevue, WA: Valve Software.

Siddiqui, A. (2013, March 27). Playtime Online: MasterPlanners:WhatDoesSimCity-based Curriculum Look like? Retrieved from http://www.instituteofplay.org/awsm /playtime-online/master-planners-whatdoes-simcity-based-curriculum-looklike/

Valve Software. (2012, April 27). Portal 2 Perpetual Testing Initiative [YouTube Video]. Retrieved from http://www.youtube. com/watch?v=b7rZO2ACP3A

Vic. (2012, May 2). Vic's Thoughts on: The Portal 2's Perpetual Testing Initiative DLC; Or Why Portal 2's Future Is Looking Very Bright. Retrieved from http:// lambdageneration.com/posts/vicsthoughts-on-the-portal-2s-perpetualtesting-initiative-dlc-or-why-portal2s-future-is-looking-very-bright/

Weisstein, E.W. (2007). Fundamental Forces. Retrieved from http://scienceworld.wol fram.com/physics/FundamentalForces. html

Whitcomb, D. (2008, October 4). World of Warcraft as a teaching tool. Retrieved from http://wow.joystiq.com/2008/10/04/ world-of-warcraft-as-a-teaching-tool/

Wilde, T. (2012, April 26). Portal 2 "Perpetual Testing Initiative" release date announced. Retrieved from http://www. pcgamer.com/2012/04/26/portal-2-per petual-testing-initiative-release-dateannounced/ 


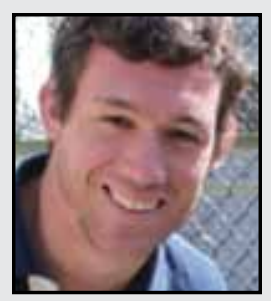

Cameron Pittman is in his fourth year of teaching science after graduating from Vanderbilt University with a B.A. in physics and Belmont University with an M.A. in teaching. He currently teaches at LEAD Academy, a charter high school in Nashville, TN. Combining his interests in science, video games, and education, he has spent the last two years exploring Portal 2 as a physics laboratory setting for high school classes. He runs a website, Physics with Portals, which he uses to demonstrate sample experiments students can perform in class. Valve Software recently followed the progress of Cameron's 11th grade physics classes, which were among the first to make Portal 2 a centerpiece of laboratory exercises. 